\title{
EXCAVACIONES ARQUEOLÓGICAS EN EL YACIMIENTO EMIRAL DE CABEZO PARDO (SAN ISIDRO-GRANJA DE ROCAMORA, ALICANTE). PRIMEROS RESULTADOS
}

\author{
ARCHAEOLOGICAL EXCAVATIONS IN THE ISLAMIC SITE OF CABEZO PARDO (SAN ISIDRO-GRANJA DE \\ ROCAMORA, ALICANTE). FIRST RESULTS
}

\author{
JUAN ANTONIO LÓPEZ PADILLA \\ TERESA XIMÉNEZ DE EMBÚN SÁNCHEZ \\ Museo Arqueológico Provincial de Alicante
}

\section{INTRODUCCIÓN}

La particular conformación geoecológica de la cuenca baja del río Segura constituye, sin lugar a dudas, una de las claves principales que explican la importancia y variedad del patrimonio arqueológico presente en esta zona del sur de Alicante. A pesar de las numerosas e intensas transformaciones a las que ha sido sometida a lo largo de la historia, y que en poco más de trescientos años han trocado de manera casi completa su paisaje, en muchos de sus recodos se esconden aún hoy, semiocultas tras el mudo testimonio de sus yacimientos arqueológicos, las claves para desentrañar el relato de un pasado hilvanado en un larguísimo rosario de grandes y pequeños esfuerzos por dominar la naturaleza.

Muchos son, en efecto, los episodios de que consta ese pasado, y algunos de los que recabaron nuestra atención remontan a las postrimerías de la prehistoria, cuando en estos terrenos se dirimía la solución divisoria de dos culturas que hallaban aquí el espacio para su diferencia y también para su encuentro y relación: el Grupo Argárico y el Grupo del Prebético Meridional Valenciano. En ese sentido, puede afirmarse que la Vega Baja del Segura conforma un área de trascendental importancia para la investigación de la Edad del Bronce del Sureste peninsular, tal y como ha puesto de manifiesto cerca de medio siglo de investigación (Tarradell, 1950; Lull, 1983; Hernández, 1985; idem, 1997; Jover y López, 1995; idem, 2004).

A pesar de ello, y como resultado de la propia dinámica de los programas de investigación desarrollados durante las últimas décadas, en lo que atañe a este período histórico y en comparación con la información disponible para las vecinas cuencas del Vinalopó y el Serpis, la Vega Baja del Segura adolece de una notable carencia de datos, debiéndonos aún contentar básicamente con los procedentes de las antiguas excavaciones de Julio Furgús (1937) y de los posteriores análisis y estudios de los materiales exhumados por él (Lull, 1983; Soriano, 1984; Simón, 1997).
Tratar de enmendar esta carencia en la medida de lo posible fue uno de los objetivos esenciales marcados por el proyecto que, impulsado desde el MARQ -Museo Arqueológico de Alicante- se inició en otoño de 2005 bajo la dirección de uno de nosotros, y que como primer paso fijó el desarrollo de un programa de prospección intensiva de los yacimientos argáricos del Bajo Vinalopó y del Bajo Segura y de su entorno inmediato (López Padilla, 2006). En cuanto a los modelos de gestión y jerarquización del espacio, los resultados de dicho trabajo permitieron situar esta zona al mismo nivel de documentación que otras áreas aledañas, permitiendo reconocer y comenzar a perfilar las características y organización del territorio argárico en su frontera más oriental.

Durante dichos trabajos se documentó de forma reiterada la presencia de restos de ocupaciones posteriores en un número considerable de los emplazamientos prehistóricos prospectados, y una alta coincidencia locacional en el patrón de asentamiento con una serie de enclaves medievales, ya conocidos (Azuar y Gutiérrez, 1999; Gutiérrez, 1996). Así, sobre los yacimientos prehistóricos de Cabezo Soler (Rojales), Laderas del Castillo (Callosa de Segura), Pic de les Moreres (Crevillent), El Castellar (Elche) o El Morterico (Abanilla) se localizan restos de época tardorromana y/o altomedieval que permiten sospechar una cierta sintonía entre las estrategias subyacentes a la estructuración política y económica de este territorio, en dos momentos tan distantes en el tiempo como son la Edad del Bronce por una parte, y el ocaso y transformación del mundo clásico y los inicios y consolidación del Estado andalusí peninsular, por otra.

La selección del Cabezo Pardo como pieza angular del desarrollo de la segunda fase del proyecto, en la que se contemplaba la excavación en extensión de alguno de los yacimientos prospectados nunca persiguió, como objetivo primordial, generar datos con los que afrontar los interrogantes planteados en la problemática histórica asociada a ese último período, sino que en primera instancia se ha perseguido solventar la 
carencia de información arqueológica relativa al Grupo Argárico en el Bajo Segura.

No obstante esto, a nadie podía escaparse la importancia histórica del Cabezo Pardo durante los primeros siglos posteriores a la conquista islámica de la Península, cuestión que ya había sido puesta de manifiesto en diversos trabajos en los que se había identificado de forma precisa este asentamiento con el Tall al-Jațta $\bar{b}$ mencionado en las crónicas de al 'U $\underline{d} r \hat{\imath}$, entregado por Teodomiro a 'Abd al-ŶYabbār b. Nadir en calidad de dote por el matrimonio de éste con su hija, enlace que daría origen posteriormente al poderoso linaje murciano de los Banu Jattāa (Gutiérrez, 1995b).

Teniendo en cuenta estos precedentes, cabe añadir que este trabajo sólo pretende ser una presentación de los primeros datos arqueológicos relativos al asentamiento emiral de Cabezo Pardo y una nueva aproximación a su valoración en el contexto de la Vega Baja del Segura.

\section{EL ASENTAMIENTO EMIRAL DE CABEZO PARDO}

El yacimiento de Cabezo Pardo se encuentra emplazado a $59 \mathrm{~m} \mathrm{~s} / \mathrm{n} / \mathrm{m}$, sobre una elevación destacada del conjunto conocido como Cabezos de los Ojales -topónimo sin lugar a dudas derivado de los diversos manantiales conocidos en el paraje desde la antigüedad y todavía activos en su mayoría hasta hace poco tiempo -por cuyas cimas discurre actualmente la divisoria de los términos municipales de San Isidro y Granja de Rocamora, en Alicante (Fig. 1).

Desde un punto de vista geomorfológico constituye un afloramiento que, por su litología y características estructurales, puede atribuirse al Triásico de la zona interna de las cordilleras béticas, concretamente al Alpujárride. En su base presenta una litología formada por filitas con cuarcitas, quedando más arriba en la serie filitas y metabasitas y un techo de carbonatos con alto componente magnésico -dolomías. Todo el

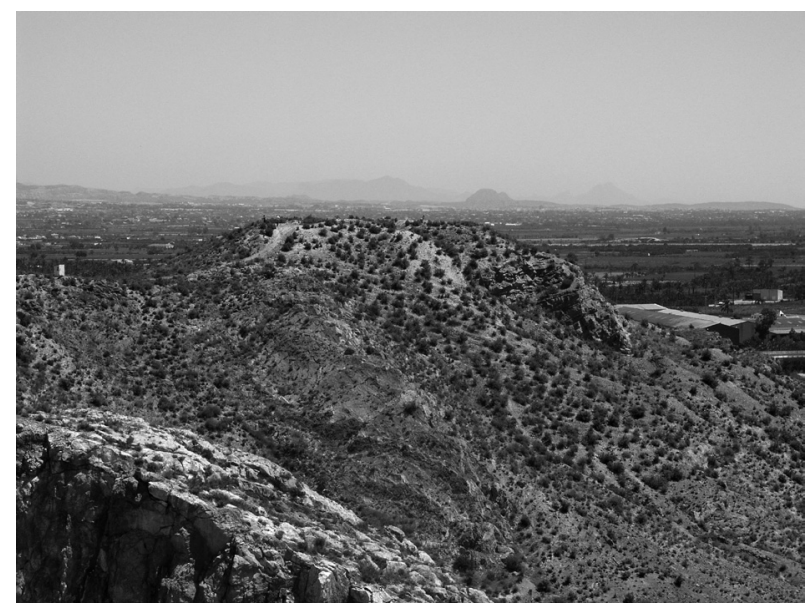

Figura 1: Vista general del Cabezo Pardo. conjunto se encuentra altamente diaclasado y fisurado, con rellenos de calcita recristalizada ${ }^{1}$.

$\mathrm{Su}$ reconocimiento como yacimiento arqueológico se remonta a los primeros años del siglo XX, cuando al parecer el propio L. Siret, o más probablemente Pedro Flores o alguno de sus hijos, llevó a cabo excavaciones arqueológicas en el emplazamiento, fruto de las cuales son un conjunto de objetos cerámicos, líticos y malacológicos que actualmente forman parte de la Colección Siret que se custodia y conserva en el Museo Arqueológico Nacional de Madrid, y a los que acompañaba un lote documental referido a dichas actuaciones que fue dado a conocer hace ya algunos años (Simón, 1999). A pesar de que en dichos documentos se hacía referencia de forma imprecisa a un lugar denominado «Cabezo de la Granja» hay pocas dudas de que, como afirma J. L. Simón (1999: 254), se trate del yacimiento de Cabezo Pardo.

Durante las prospecciones realizadas en 2005 se le había calculado, a partir de los datos proporcionados por la fotografía aérea, una extensión de $5.300 \mathrm{~m}^{2}$ pero las medidas tomadas in situ nos revelaron un área con sedimento arqueológico considerablemente menor, de unos $3.100 \mathrm{~m}^{2}$. El yacimiento se ha conservado en mal estado, habiéndose visto afectado por la erosión y la acción antrópica -todavía resulta claramente visible el trazado de unas pistas de motocross que lo cruzaban de parte a parte -y también por numerosas remociones incontroladas, principalmente en la cima, donde se localizan hasta media docena de fosas y trincheras de enormes proporciones entre las que se amontonan tres grandes terreras.

Los trabajos arqueológicos emprendidos en 2006 han afectado por el momento a una pequeña superficie de apenas $120 \mathrm{~m}^{2}$, trazada sobre uno de los puntos de la cima en la que afloraba un mayor número de estructuras murarias, y donde las intervenciones incontroladas habían alcanzado una mayor profundidad. Con ello se confiaba en adquirir con celeridad datos referentes a las cronologías atribuibles a las estructuras exhumadas y sobre la naturaleza del paquete estratigráfico conservado en el yacimiento.

Como resultado de estos trabajos, durante las campañas de 2006 y 2007 se ha podido corroborar que sólo una de las estructuras arquitectónicas visibles con anterioridad al inicio de los mismos pertenecía a la fase más reciente de la ocupación del yacimiento, correspondiendo el resto a viviendas y estructuras arquitectónicas del II milenio BC. Por otro lado, esta unidad constructiva-UH n ${ }^{\circ} 1$-se revela como una habitación de proporciones considerables, única de la que se pueden reconocer al menos tres de los cuatro lienzos murarios que hipotéticamente la delimitarían. Por su tamaño y por el ancho que presenta el vano de acceso -UE 2009 -cabría plantear la posibilidad de que no se tratase de un ambiente doméstico más (Fig. 2).

El tipo de derrumbe de paredes y techumbre que se ha reconocido en su interior invita a pensar en un contexto de abandono paulatino en el que se produce 


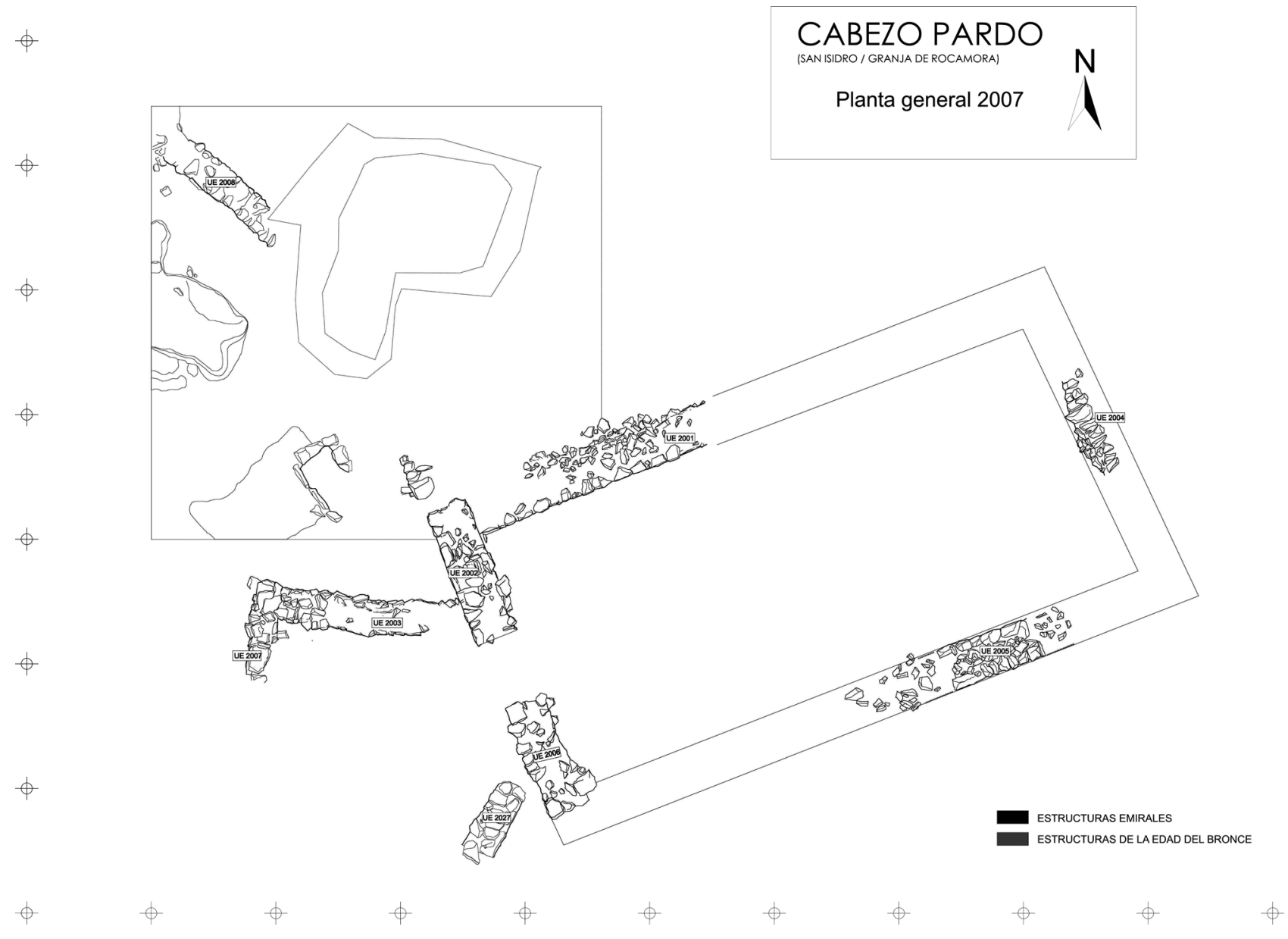

Figura 2: Planta general del área excavada del yacimiento de Cabezo Pardo.

la ruina progresiva del edificio, pues los materiales cerámicos localizados aparecen muy mezclados con los cascotes, a diferentes alturas, y sin señales de incendio ni de destrucción súbita. La ausencia de objeto alguno sobre la exigua superficie de pavimento conservada y lo incompleto del estado de conservación de los muros impide, por el momento, apuntar ninguna hipótesis plausible acerca de la funcionalidad concreta que pudo haber tenido este edificio originalmente.

La comprobación de que el pavimento UE 3001 y los propios cascotes de las paredes y techo derrumbados pudieron haberse visto afectados por remociones posteriores al abandono vino del registro de una gran fosa que afectó el umbral y la parte occidental del interior de la habitación, y con la que posiblemente se buscaba el aprovisionamiento de material constructivo para ser reaprovechado en alguna construcción, obviamente emplazada en otro lugar (Fig. 3).

Lo que han podido determinar con claridad los trabajos realizados es que la zanja de cimentación del edificio afecta en un tramo de aproximadamente 0,50 $\mathrm{m}$ de profundidad al paquete sedimentario prehistórico, de lo que se deduce que el pavimento de la habitación se encontraba en una cota entre 0,70 y $0,50 \mathrm{~m}$ por debajo del nivel de suelo al exterior del edificio (Fig. 4).

Todo parece indicar que esta ocupación de época emiral pudo ofrecer -cuando menos en el área hasta ahora registrada - un patrón urbanístico disperso conformado por viviendas de tamaño considerable

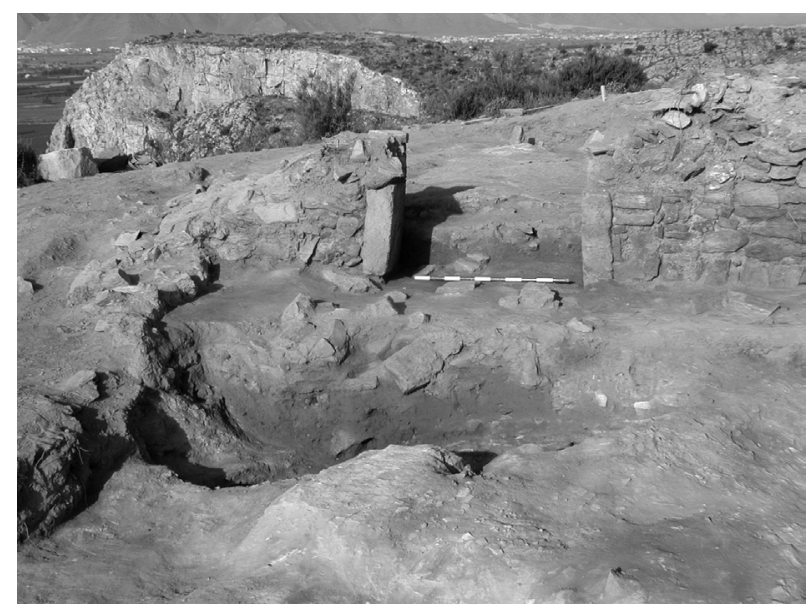

Figura 3: Fosa de expolio (UE 2019) localizada en la parte SO de la UH 1. 


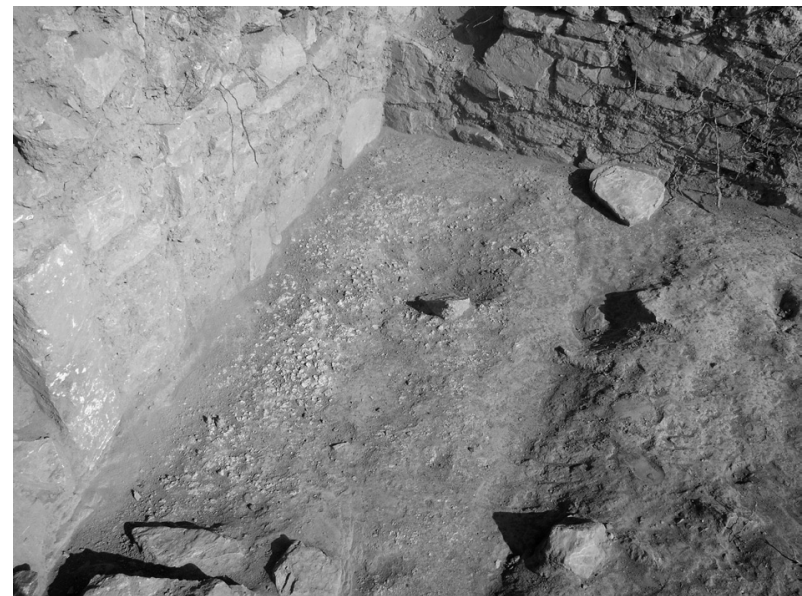

Figura 4: Pavimento (UE 3001) conservado en la esquina NO de la UH 1.

distribuidas a lo largo de la superficie del cerro a cierta distancia unas de otras, y que el Tall al-Jattāa b citado en los textos de $a l$ - 'Ud $r i \hat{i}$ estaría integrado no sólo por las casas que se alzaban sobre el Cabezo Pardo sino también por las que ocupaban la cima amesetada del cercano Cabezo de las Fuentes (Fig. 5), ya en el Término Municipal de Granja de Rocamora. La prospección superficial realizada en éste último ha revelado la existencia de un exiguo relleno arqueológico asociado a un número considerable de estructuras, de tamaño y factura muy similares a los de la $\mathrm{UH} \mathrm{n}^{\circ} 1$ de Cabezo Pardo, sobre las que se localizan numerosos fragmentos cerámicos de cronología emiral.

\section{LOS MATERIALES ARQUEOLÓGICOS}

Aunque por toda la superficie del Cabezo Pardo es fácil encontrar materiales -fundamentalmente cerámicos de cronología medieval, en este breve estudio nos centraremos en el análisis de aquellos conjuntos asociados estratigráficamente con las estructuras islámicas

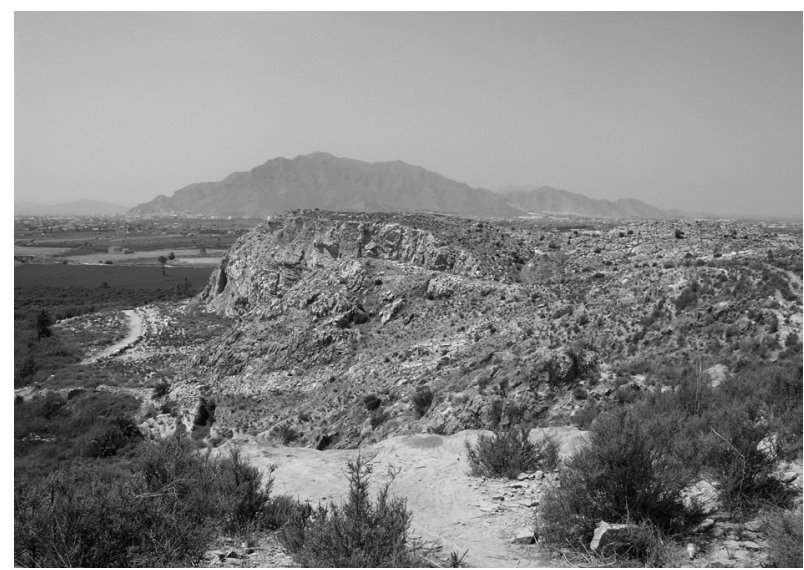

Figura 5: Vista general del Cabezo de las Fuentes tomada desde la cima del Cabezo Pardo. excavadas que, como hemos visto, se reducen por el momento a la UH 1. A excepción del material hallado en la UE 1000, de origen amplio e indeterminado, dos son los estratos que más información han aportado: las UEs 1001 y 1029 .

La UE 1001, documentada a lo largo de la primera campaña de excavaciones en el año 2006, se ha identificado como un estrato originado por el derrumbe y posterior erosión de las paredes occidentales y suroccidentales de UH 1. El estrato se compone en su mayoría por bloques de caliza y de calcoarenitas, entre los cuales se hallaron mezclados abundantes restos arqueológicos tanto de tipo faunístico como cerámico.

La UE 1029, en este caso excavada en la campaña del año 2007, se define como un estrato compuesto en su mayoría por arcillas de color castaño, con algunos bloques de caliza y abundante material de carácter arqueológico y orgánico. Se trata de un estrato que colmata una fosa de expolio (UE 2019) identificada en la mitad occidental de la UH 1. En sus cotas superiores todavía presenta una gran cantidad de bloques que podrían pertenecer a partes alteradas del derrumbe de las paredes, es decir, a la UE 1001.

Así pues, todos los objetos de carácter arqueológico registrados en estas unidades se documentaron en contextos de deposición secundaria, puesto que el pequeño tramo de pavimento conservado intacto en el ángulo noroccidental de la UH 1 apareció sin ningún material depositado sobre él. A pesar de que ello comporta evidentes limitaciones para la interpretación funcional de esta habitación, el conjunto cerámico registrado en todas las unidades estratigráficas relacionadas con su abandono y amortización resulta suficientemente significativo.

Para facilitar el análisis y exposición de los materiales del Cabezo Pardo hemos considerado conveniente basar nuestro estudio en la tipología desarrollada por S. Gutiérrez (1996), ya que en ella se encuentran integradas las formas más destacadas del mundo tardío y la Alta Edad Media del SE Peninsular. Con esta breve puntualización pretendemos no resultar repetitivos en las descripciones, de forma que en el texto sólo se hará referencia a las Series y Subtipos utilizados por la autora.

\subsection{CERÁMICA A MANO O TORNETA}

\subsubsection{Marmita}

Una de las primeras formas que queremos destacar dentro de este conjunto de cerámicas a mano es la pieza CP'06-1001-18 (Fig. 6), una carena baja perteneciente a una marmita de tendencia troncocónica similar a la forma M.1.2. de la Serie 1 de Gutiérrez. Presenta una textura basta con abundante desgrasante mineral de mediano tamaño y pasta de color anaranjado con pared externa reductora. Podría tratarse de un ejemplar de marmita cuya cronología se sitúa entre 
finales del s.VII e inicios del s.VIII, bien documentada en yacimientos como La Alcudia (Elche), los Cabecicos Verdes (Orihuela), en la Villa de Fontcalent (Alicante) o en el Horizonte II del Palatium del Tolmo de Minateda, donde ha sido fechada a mediados del s. VIII (Gutiérrez, 2007, 306, fig. 7). Aunque se trata de un recipiente de claro origen romano tardío no resulta extraña su presencia en contextos más avanzados, ya que como veremos a lo largo de este trabajo, estamos ante producciones que cuentan con un uso prolongado en el tiempo.

Las marmitas son el tipo cerámico más representativo y abundante del Cabezo Pardo. Aunque podamos contar con algún ejemplar de finales del s.VII, la mayoría se asocian a las formas avanzadas de la Serie 4 de Gutiérrez, identificadas como las primeras formas islámicas que conectan con la tradición del mundo romano tardío.

La pasta, muy similar en todos los ejemplares documentados, es de textura bizcochada, con abundante desgrasante mineral de mediano tamaño. El color varía de los rojos-anaranjados a los ocres, aunque parece haber cierto predominio del primero. La tipología de los bordes es siempre la misma, el característico borde reentrante de labio ligeramente apuntado. Algunos de los fragmentos conservan marcas de fuego en su cara externa, lo que refuerza su función como contenedor culinario. Las marmitas del Cabezo Pardo se corresponden con los subtipos M.4.1.1 y M.4.1.2, es decir recipientes de base plana de cuerpo de tendencia cilíndrica con paredes que convergen ligeramente para

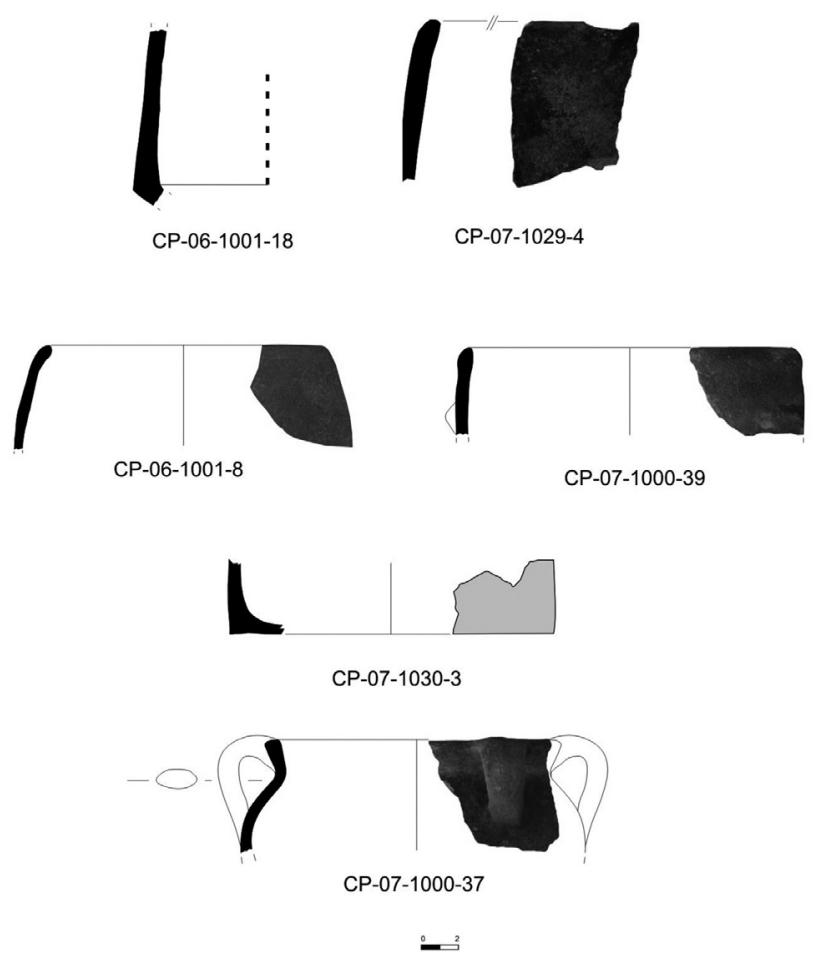

Figura 6: Materiales emirales del Cabezo Pardo. formar la boca. Varios ejemplares presentan lengüetas horizontales -CP'07-1000-39 (Fig. 6) y CP'06-100110 - y uno de los fragmentos conserva un pequeño pico vertedor formado por una impresión digital en el borde -CP'07-1029-4 (Fig. 6)-, el resto pueden agruparse en la forma simple representada por el subtipo M.4.1.1.

Las formas presentes en el Cabezo Pardo son comunes en yacimientos emirales cuya cronología los sitúa entre mediados del s.VIII y el s. IX. Podemos encontrarlas bien representadas en contextos cercanos como Laderas del Castillo (Callosa del Segura), los Cabecicos Verdes (Orihuela), el Castillo de Orihuela, el Cabezo del Molino (Rojales) o el Zambo (Novelda).

Cabe destacar que no se ha encontrado ninguna marmita con decoración incisa simple o con peinado, elemento asociado a las formas M.4.2. más características de la segunda mitad del s. X y principios del s. XI.

Dentro de estas formas a mano definidas como marmitas, el Cabezo Pardo presenta una pieza de pequeñas dimensiones -CP'07-1000-37 (Fig. 6)- cuya boca rondaría los 8 o $10 \mathrm{~cm}$ de diámetro. Se trata de un recipiente de cuerpo globular, sin cuello, borde exvasado y labio recto, con un asa de implantación vertical y sección ovalada que parte desde el mismo labio y parece llegar hasta el inicio del hombro. La pasta es oxidante, de textura bizcochada y abundante desgrasante de mediano tamaño con destacados puntos de color blanco. Su cara externa se conserva ennegrecida. Al igual que nos pasara con la pieza CP'06-1001-18 descrita al inicio de este estudio, esta pequeña marmita no resulta sencilla de datar, ya que sus paralelos, por tipología, dimensiones y tipo de desgrasante se asemejan mucho a las formas del subtipo M.6.5. documentadas en yacimientos de finales del s.VII e inicios del s.VIII.

\subsubsection{Jarro}

Además de las marmitas, el Cabezo Pardo cuenta con otras formas destacadas de la cerámica a mano medieval, como un jarro con perfil en «S»-CP'06-100116 (Fig. 7)-y un contenedor de grandes dimensiones -CP'07-1001-5 (Fig. 8).

El probable jarro presenta un borde exvasado y labio redondeado del que se conserva el pico vertedor realizado por presión lateral. Se trata de un ejemplar de pasta color grisácea con abundante desgrasante mineral de mediano tamaño. Se corresponde con la forma M.18.1 y cuenta con su paralelo más cercano en el yacimiento del Zambo (Novelda) lo que le confiere una cronología del s.IX.

\subsubsection{Contenedor}

En el caso del contenedor contamos con tres fragmentos que por el tipo de pasta y grosor podrían pertenecer a una o varias piezas muy similares. Por un lado tenemos un borde de tendencia recta con labio biselado al 


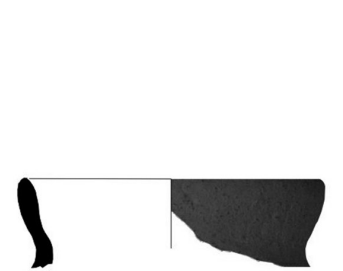

CP-06-1001-15

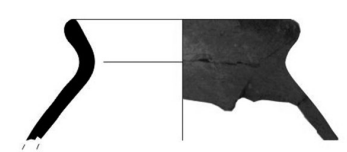

CP-06-1001-16

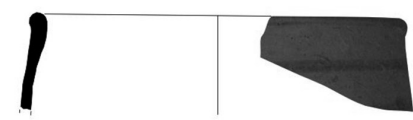

CP-07-1001-7
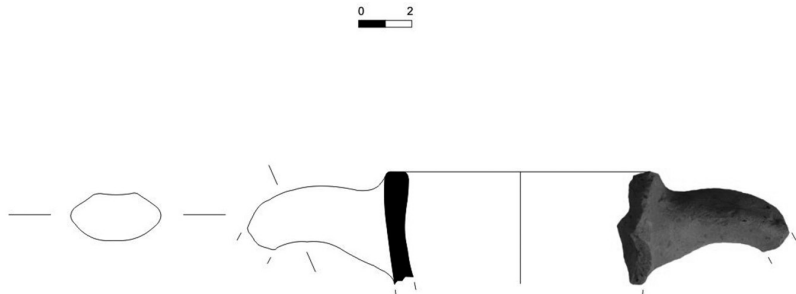

CP-07-1000-38

$\stackrel{2}{2}$

Figura 7: Materiales emirales del Cabezo Pardo.

exterior y arranque de asa al comenzar la curvatura del hombro. También contamos con un fragmento de pared de tendencia ovoide con lengüeta indicada y base plana de pared abierta. Los tres fragmentos presentan una pasta de textura basta, cocción oxidante y desgrasante mineral de gran tamaño de un característico color rojizo.

Aunque no parecen responder de forma concreta, a ninguna de las formas conocidas de tinaja islámica, su tipología se asemeja bastante al subtipo M.10.3 representado por un contenedor de grandes dimensiones hallado en el yacimiento del Zambo (Novelda).

\subsection{CERÁMICA A TORNO}

\subsubsection{Jarro / jarra}

La cerámica a torno del Cabezo Pardo se encuentra representada principalmente por jarras y jarros de diverso tipo, de los que destacaremos tres ejemplares por ser los más representativos del conjunto.

La pieza CP'06-1001-19 (Fig. 8) es una base de jarra que por su pequeño diámetro y la apertura de la pared conservada podría responder al subtipo T.20.2. Se trata de una pieza cuya singularidad se encuentra en las marcadas líneas de torno que presenta tanto al interior como al exterior de la pared.

La pieza CP'06-1001-26 (Fig. 8) es una de las formas más completas que presenta el yacimiento. Se trata de un borde y parte de la pared de un recipiente de mediano tamaño con boca y cuello estrecho. En la misma unidad estratigráfica se encuentra una base plana -CP'06-1001-13 (Fig. 8)- que por el tipo de pasta, oxidante con abundante desgrasante mineral de mediano tamaño, parece pertenecer también a esta pieza. El borde es recto y su labio moldurado y presenta una decoración pintada en óxido de hierro sobre el hombro a base de finos trazos paralelos. Sin duda se trata de una jarra de la Serie 11 que por su borde liso, sin arista, responde al subtipo T.11.1.1. Estas jarras son muy comunes en contextos que van de mediados del s.VIII al s. X, encontrándose bien documentadas en yacimientos cercanos como el Zambo (Novelda), el Cabezo del Molino (Rojales) o el Cabezo Soler (Rojales).

En el caso de la pieza CP'07-1000-38 (Fig. 7), nos encontramos ante algún tipo de jarra más indeterminado. Se trata de un recipiente de pasta oxidante de color amarillento con desgrasante mediano y variado. Presenta un borde recto y labio de sección cuadrangular desde donde arranca un asa vertical de
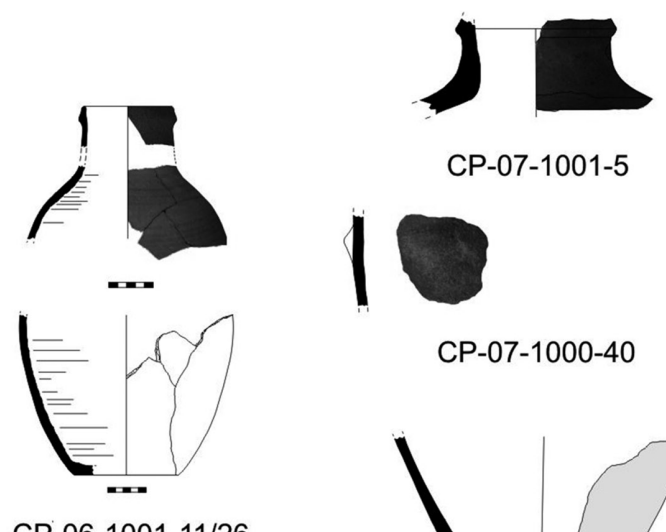

CP-07-1001-5

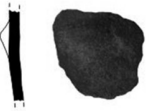

CP-07-1000-40

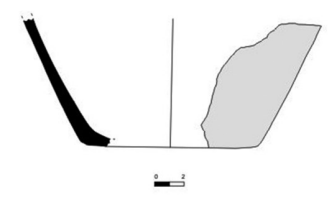

CP-06-1000-29

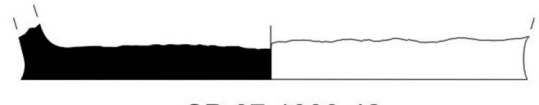

CP-07-1000-42

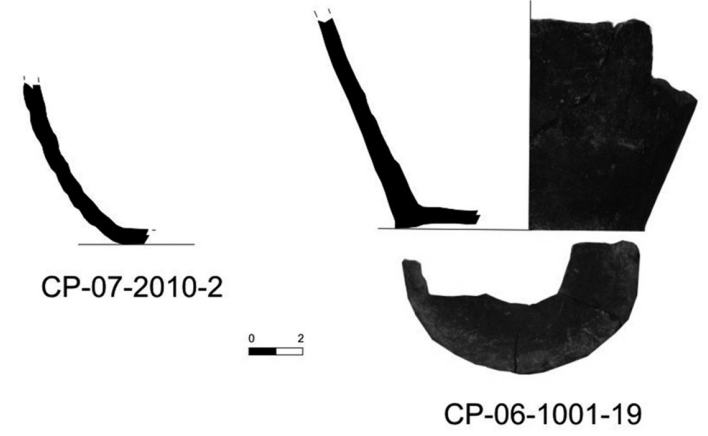

Figura 8: Materiales emirales del Cabezo Pardo. 
sección oval con dos nervios centrales indicados. Un ejemplar de similares características fue publicado por S. Gutiérrez $(1996,354)$ en relación con los materiales hallados en el cercano yacimiento del Cabezo de las Fuentes.

Además de los tipos descritos, en niveles superficiales nos encontramos, aunque más fragmentada, cerámica similar a la ya mencionada: numerosos fragmentos de marmita, bordes con y sin mamelón, algunas bases de jarra y numerosos fragmentos informes de cerámica común indeterminada. Entre todos ellos llama la atención la presencia de tres fragmentos informes de cerámica común pintada que presentan pastas amarillentas, con desgrasante de pequeño tamaño y una decoración pintada monocroma en óxido de hierro a bandas que podrían pertenecer a algún tipo de jarro de cronología algo más avanzada -CP'07-1001-7 (Fig. 7).

Como ya se ha mencionado, muy próximo al Cabezo Pardo se encuentra el Cabezo de las Fuentes, cerro contiguo en el que se visualizan en superficie algunas estructuras de aparente planta rectangular y abundante material cerámico. Prospecciones superficiales en éste área nos han permitido reconocer la presencia de un material de clara similitud con el existente en nuestro yacimiento (Fig. 9). Cerámicas en su mayoría de pastas oxidantes y textura bizcochada con desgrasantes de mediano tamaño cuyas formas responden a bases planas y bordes reentrantes con labio apuntado de marmitas M.4.1. y algún borde de jarra a torno de la Serie 11, junto a otros fragmentos variados difíciles de determinar. Aunque se trata de un material escaso y rodado se puede decir que el conjunto corresponde a una cronología emiral, asociando así la ocupación
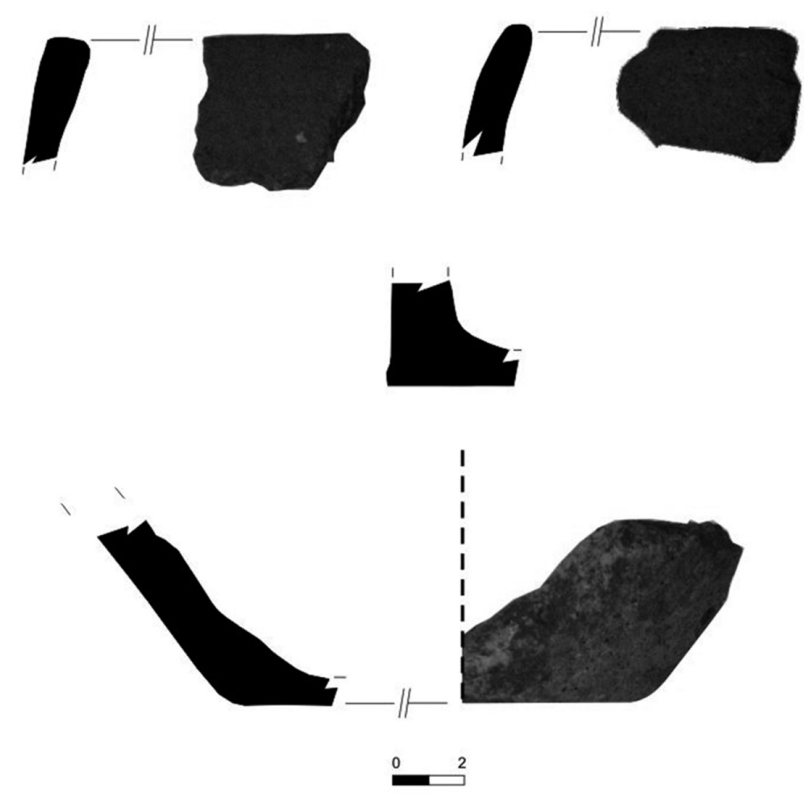

Figura 9: Materiales del Cabezo de las Fuentes. del Cabezo Pardo y la del Cabezo de las Fuentes a un mismo momento.

\section{HACIA UNA REPRESENTACIÓN ARQUEOLÓ- GICA DE TALL AL-JATT $\bar{A} B$}

Analizados sus materiales cerámicos, y a falta de otros documentos arqueológicos que pudieran resultar más explícitos en este sentido, se puede afirmar que el yacimiento del Cabezo Pardo, en su última fase de ocupación, presenta un conjunto especialmente significativo de formas cerámicas características del Sureste Peninsular de época emiral (Gutiérrez, 1996), que cronológicamente abarcaría la horquilla comprendida desde mediados del s. VIII hasta finales del s. IX.

Por otra parte, la excavación del interior de la UH n. ${ }^{\circ} 1$ permite proponer un momento de abandono en torno a finales del siglo IX, el cual no debió acontecer de manera repentina a tenor de la ausencia de material arqueológico depositado sobre los escasos restos de pavimento registrados, ni adquirir tampoco un carácter catastrófico. Tras dicho abandono, y cuando el lugar se encontraba ya en estado ruinoso, se excavaron una serie de fosas que alteraron los propios derrumbes y que explican también la ausencia de niveles de pavimentación en el sector suroccidental de la UH n. ${ }^{\circ} 1$, afectados por una de ellas, de la que posiblemente se extrajo el material pétreo empleado en la construcción del vano de acceso.

El Cabezo Pardo es un yacimiento cuya investigación acaba de comenzar y del que sólo se cuenta con dos campañas de excavaciones. Éstas han permitido, no obstante, constatar la ausencia de materiales arqueológicos que sobrepasen de forma significativa el s. IX, lo que sitúa su abandono paulatino hacia inicios del s. X, en una franja cronológica coincidente con la que parece marcar también la desaparición de otros enclaves contemporáneos y todo ello en concurrencia con una reorganización territorial que llevó implícito el desarrollo de un nuevo sistema de regadío, vinculado a la ciudad de Orihuela.

Este proceso transformador, así como la caracterización del sistema de organización territorial de época emiral en la Vega Baja del Segura ya fue objeto de análisis por parte de S. Gutiérrez y R. Azuar (1999), quienes emplearon, entre otras fuentes, los datos resultantes de un estudio arqueológico de carácter extensivo (Gutiérrez, Moret, Rouillard y Sillières, 1999) que permitía marcar, a partir de la localización de los yacimientos de esta cronología, el área perimetral ocupada por la zona de marjal en esos momentos.

Estos yacimientos que ocuparán las zonas deprimidas del interior del valle, entre el borde montañoso y el llano fluvial, se situarán principalmente en las laderas de los relieves cercanos o en cabezos de poca altura diseminados y aislados en mitad del llano, como en el caso del Cabezo Pardo. 


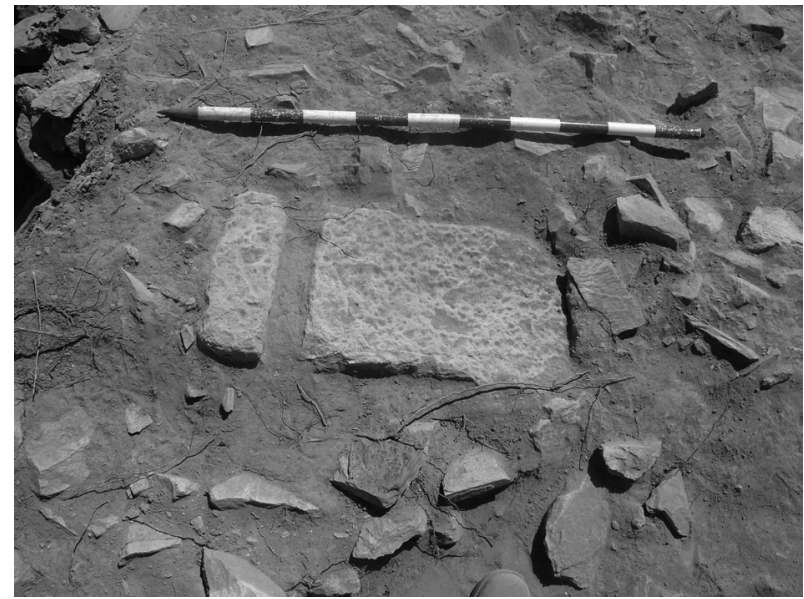

Figura 10: Material constructivo reutilizado hallado en el derrumbe de las estructuras de la UH 1.

En ellos encontramos a pequeños grupos de población identificados como comunidades independientes de origen indígena para quienes estas áreas marginales, teóricamente fuera del control de los propietarios latifundistas, suponen un sistema de subsistencia gracias a un aprovechamiento inteligente del medio que les permite desarrollar estrategias productivas diversificadas.

La temprana llegada de población islamizada a estas tierras, atestiguada por el surgimiento de yacimientos como el Cabezo Pardo, supondrá también la introducción de nuevas técnicas de irrigación artificial a pequeña escala, en las que se aprovecharían las zonas bajas fertilizadas por las avenidas periódicas (Gutiérrez, 1995b). Estas primeras experiencias se vinculan materialmente a la presencia de arcaduces, un tipo cerámico que implica el desarrollo de ruedas hidráulicas de tracción animal, pero del que por el momento no se ha registrado ningún ejemplar en nuestro yacimiento.

El mencionado origen indígena de las poblaciones del Bajo Segura no sólo se atestigua en fuentes escritas como las del geógrafo al- 'Udrî - quien se refiere a esta área como región de muladíes (Azuar y Gutiérrez, 1999: 203)- sino que también se refleja en la cultura material que presentan estos yacimientos.

Como hemos podido comprobar, el Cabezo Pardo cuenta con algunos materiales que conectan la tradición romano-tardía con la islámica, a lo que se suma ahora la reutilización de material constructivo procedente de construcciones anteriores en los paramentos de los muros (Fig. 10). En la excavación de la UH n. ${ }^{\circ} 1$ se pudo constatar la existencia de un significativo número de sillares presentes tanto en el derrumbe de la estancia (UE 1001) como formando parte de los paños de las paredes que aún se conservan en pie. Posiblemente estos grandes bloques, utilizados a modo de jambas en el vano, podrían tener su origen en alguna de las villas de tradición tardía situada en el llano, probablemente en algún lugar indeterminado al pie del cabezo.
Otro testimonio de esta relación entre ambas poblaciones se encuentra ligado, como ya se ha comentado, a la alianza matrimonial establecida entre el yundí 'Abd al-Ŷabbār b. Nadir y la hija del noble visigodo Teodomiro. A dicha unión le acompañó como dote la entrega de dos alquerías situadas en el bajo Segura, la qarya Tarsa y la qarya (...) Tall al-Jațtâb. Gracias a la información geográfica aportada por al- 'Ud $r i \hat{\imath}$ se sabe que la primera de ellas se encontraba a tres millas de Elche mientras que la segunda se encontraría a unas ocho millas de Orihuela. Una ubicación geográfica que en el caso de la segunda de las alquerías va unida a la utilización del topónimo Tall (que hace referencia a un emplazamiento sobre una loma, cerro o montículo), y que ha permitido a S. Gutiérrez (1995b) plantear su más que posible identificación con el yacimiento que aquí nos ocupa, situado a una distancia aproximada de doce kilómetros de Orihuela.

Por último, cabe añadir además el hallazgo de un enterramiento referenciado en los Cuadernos de la Colección Siret del Museo Arqueológico Nacional que, de acuerdo con la descripción realizada en ellos por Pedro Flores, capataz de Siret y descubridor del hallazgo, se trataba de una inhumación en fosa de metro y medio de largo por cuarenta centímetros de ancho en la que se especifica que los restos óseos fueron localizados «(...) al lado de una risca y pedriza tapada con cuatro losas» (Simón, 1999: 254). El enterramiento, del que además de la descripción se conserva un dibujo esquemático a modo de boceto, fue localizado en un emplazamiento denominado por él «Cabezo de la Granja», posiblemente el Cabezo de las Fuentes, tal y como apunta J. L. Simón (1999).

La presencia de asentamientos de este tipo sobre cerros ocupados con anterioridad por comunidades de la Edad del Bronce es un fenómeno arqueológico muy ampliamente representado, y ciertamente más acusado en el ámbito del sur de Alicante, Murcia y Almería (Castro, et alli, 1999; Cressier, et alli, 1991). En la Vega Baja del Segura los casos registrados son bien conocidos: Cabezo Pardo, Laderas del Castillo de Callosa, El Morterico... a los que cabe añadir otros también conocidos en el Vinalopó, como el Zambo, en Novelda (Fig. 11). Esto plantea indudablemente la cuestión de cuáles son las razones que impulsaron la reocupación de estos enclaves prehistóricos en el s.VIII.

A nuestro juicio, no es tanto el hecho de que se ubicaran en áreas marginales fuera del control de los latifundistas (de hecho, el caso de Cabezo Pardo lo descartaría como norma general, no sólo en lo que respecta a las fuentes escritas -Teodomiro lo dona como dote nupcial- sino también desde las fuentes arqueológicas: aparecen materiales constructivos inequívocamente tardorromanos reutilizados en los muros del asentamiento emiral) sino que son áreas que, como en la Edad del Bronce, garantizan a los grupos que se asientan en ellas autonomía económica (y por consiguiente, política), en este caso con respecto a las élites 


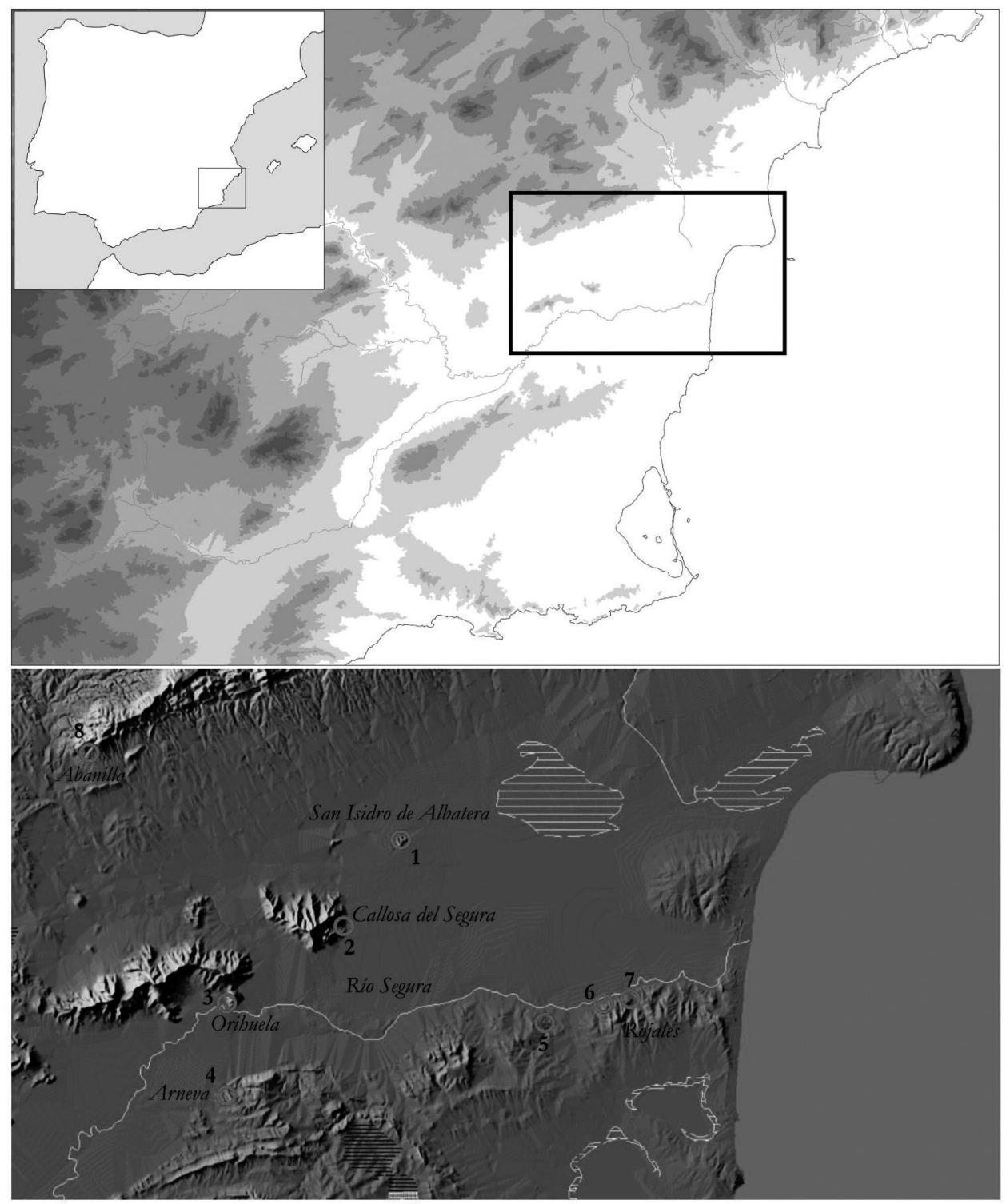

Figura 11: Mapa de localización de los yacimientos emirales del Bajo Segura.

indígenas y también con respecto al resto de linajes de los nuevos conquistadores.

La peculiar estructura que ofrecen las tribus como forma de organización social tiende a empujar a la segregación política como medio de garantizar la superviviencia. Si la elección de áreas de marjal -pero sobre todo, de zonas con manantiales, de lo que existen numerosos ejemplos en los yacimientos conocidos permitía asegurar el control de un importante abanico de recursos subsistenciales y el dominio de incipientes redes de irrigación para cultivos de huerta, su posicionamiento sobre cerros y puntos elevados implica también la necesidad -y la posibilidad-de actuar en la defensa de su propia producción y de abarcar visualmente un territorio concreto.

Esta relativa -y efectiva- autonomía de los linajes tribales confiere a las tribus una extraordinaria versatilidad que permite, en ausencia de un poder político o económico que pueda ejercer una acción coactiva y centralizadora, una notable independencia en la toma de decisiones en cuanto a la consecución de los intereses particulares de las familias dominantes y el establecimiento de sus alianzas. En el marco cronológico en el que se asiste a la fundación de estos asentamientos se dan las circunstancias propicias para el desarrollo de estas estrategias, que encontrarán su fin precisamente cuando se consolide otro escenario sociopolítico distinto, vinculado a la aparición del Califato de Córdoba y a la centralización estatal.

El retorno de las ciudades como centros de producción y de redistribución de productos agropecuarios y artesanales y la creación de nuevos núcleos subordinados a ellas hará desaparecer estos enclaves al integrar la explotación agrícola de regadío en nuevas y mayores redes de irrigación controladas por el poder político asentado en aquéllas, el cual pasará ahora a concentrar, administrar y defender los excedentes generados. 
Juan Antonio López Padilla

Teresa Ximénez de Embún Sánchez

Museo Arqueológico de Alicante

Pl. Gómez Ulla, s/n

03013 Alicante

japadi@dip-alicante.es

tximenez@dip-alicante.es

\section{BIBLIOGRAFÍA}

AZUAR, R. y GUTIÉRREZ, S., 1999: «Formación y transformación de un espacio agrícola islámico en el sur del país valenciano: El Bajo Segura (Siglos IX-XIII)», Castrum, 5, 201-210.

BECKER, H., 1991: «Informe preliminar sobre una prospección magnética efectuada en el poblado del Bronce de El Argar (Almería)», Anuario Arqueológico de Andalucía 1991. Actividades Sistemáticas II, 11-14, Sevilla.

Castro Martínez, P., Chapman, R.W., GonzÁlez MarCÉN, P., Lull, V., Micó, R., Picazo, M., Risch, R. y SANAhUJA, M ${ }^{\mathrm{a}}$ E., 1999: Proyecto Gatas 2. La dinámica Arqueológica de la ocupación prehistórica, Arqueología Monografías, Sevilla.

Cressier, P., DelaiGue, M.C., Banera, J.I., Carbonero, M A A., EgeA, J.J. y Osuna, Ma M., 1991: «Poblamiento y cultura material en un territorio elemental medieval de la Sierra de los Filabres. El Valle de Sene (Almería)», Actividades Sistemáticas II, Anuario Arqueológico de Andalucía 1991, 71-80, Sevilla.

Furgús, J., 1937: Col.lecció de treballs del P. J. Furgús sobre Prehistòria Valenciana, S.I.P. Trabajos Varios 5, Valencia

GUTIÉRREZ LlORET, S., 1988: 1988: Cerámica común paleoandalusi del sur de Alicante (siglos VII-X), Alicante.

GutiÉRREZ LlORET, S., 1995a: «El origen de la huerta de Orihuela entre los siglos VII y IX: una propuesta arqueológica sobre la explotación de las zonas húmedas del Bajo Segura», Arbor, CLI, 593. 65-94

GUTIÉRREZ LlORET, S., 1995b: «La geografía del bajo Segura según Al-'Udri (siglo XI): una propuesta de identificación de la alquería de Tall Al-Jattab», Alquibla, 1, 65-93, Alicante.

GutiÉRreZ Lloret, S., 1996: La Cora de Tudmir de la Antigüedad Tardía al Mundo Islámico: Poblamiento y cultura material, Madrid-Alicante.

GUTIÉRREZ LLORET, S., 2007: «La islamización de Tudmîr: balance y perspectivas», en P. SÉNAC, (ed.), Villes et campagnes de Tarraconaise et d'al-Andalus (VI-IX): la transition, Études Médiévales Ibériques, 275-318,

Gutiérrez, S, Moret, P., Rouillard, P. y Sillières, P., 1999: «Le peuplement du bas Segura de la Protohistoire au Moyen Âge (Prospections 1989-1990)», Lucentum, XVII-XVIII, 25-74.
HERnÁnDEZ PÉREZ, M. S., 1985: «La Edad del Bronce en el País Valenciano. Panorama y perspectivas», Arqueología del País Valenciano. Panorama y perspectivas, 101-119, Alicante.

HeRnÁndeZ PÉREZ, M. S., 1997: «Desde la periferia de El Argar. La Edad del Bronce en las tierras meridionales valencianas», Saguntum, 30, 93-114.

Jover Maestre, F. J. y LóPez PAdilla, J. A., 1997: «Una nueva propuesta del alcance espacial septentrional de las prácticas sociales argáricas», XXIV Congreso Nacional de Arqueología (Cartagena, 1997), v.2, 275286, Cartagena.

Jover MAestre, F. J. y LÓPEZ PADILlA, J. A., 2004: «21001200 BC. Aportaciones al proceso histórico en la cuenca del río Vinalopó» en L. HERNÁNDEZ y M. HERNÁNDEZ (eds.). La Edad del Bronce en tierras valencianas y zonas limitrofes, 285-302, Villena.

LÓPEZ PADILLA, J. A., 2006: El proceso histórico en el Bajo Segura y Bajo Vinalopó entre 2100 y 1200 cal BC. La prospección arqueológica, Memoria de los trabajos arqueológicos realizados, entregada a la Conselleria de Cultura de la Comunidad Valenciana.

Lull, V., 1983: La «cultura» de El Argar. Un modelo para el estudio de las formaciones económico-social prehistóricas, Madrid.

Menasanch, M. y Olmo, L., 1991: «El poblado tardorromano y altomedieval en la cuenca baja del río Almanzora (Almería) Cerro Montroy (Villaricos, Cuevas del Almanzora) Campaña de excavacaiones 1991», Anuario Arqueológico de Andalucía 1991. Actividades Sistemáticas II, 28-35. Sevilla.

MolinA LópeZ, E., 1972: «La Cora de Tudmir según Al-'Ud̆rî (s. XI). Aportaciones al estudio geográfico descriptivo del SE Peninsular», Cuadernos de Historia del Islam, 4, 41-70.

Pozo, R. y RuedA, Ma I., 1991: «El Argar 1991: Cerámica islámica», Anuario Arqueológico de Andalucía 1991. Actividades Sistemáticas II, 71- 72

TARradell Mateu, M., 1950: «La Península Ibérica en la época del Argar»V Congreso de Arqueología del Sudeste Español. Almería, 72-85. Sevilla.

REYNOLDS, P., 1985: «Cerámica tardorromana modelada a mano de carácter local, regional y de importación en la provincia de Alicante», Lucentum, IV, 245- 267

REYNOLDS, P., 1993: Settlement and pottery in de Vinalopo Valley (Alicante, Spain): AD 400-early 8thC, BAR International Series 588, Oxford.

SIMÓN GARCÍA J.L., 1999: «Actuaciones Arqueológicas de Louis Siret en Alicante», XXIV Congreso Nacional de Arqueología (Cartagena, 1997), Cartagena.

SORIANO SÁNCHEZ, R., 1985: «La cultura del argar en la Vega Baja del Segura», Saguntum, 18, 103-143. 